\title{
The influence of word valence on the right visual field advantage in the VHF paradigm:
}

\author{
Time to adjust the expectations
}

Pieter De Clercq Marc Brysbaert

Department of Experimental Psychology

Ghent University, Belgium

Keywords: Visual half field, valence, right visual field advantage, laterality

Address: $\quad$ Pieter De Clercq

Department of Experimental Psychology

Ghent University

Henri Dunantlaan 2

B-9000 Gent

Belgium

Tel. +3292646406

Fax. +3292646496

E-mail: pietdcle.declercq@ugent.be 


\begin{abstract}
Previous studies found that valence (positive vs negative vs neutral) and visual half-field (left versus right) have an influence on word reading: Words are processed more efficiently when they evoke positive feelings and when they appear in the right visual field. In the present study we tried to address previous (contradictory) reports of an interaction between valence and visual half-field. A group of 39 right-handed undergraduates completed a lexical decision task in their native language (Dutch). They responded to 300 trials with real words (50 words per valence category - positive, negative, neutral - presented once in the left visual half-field and once in the right half-field) and 300 trials with non-words. Overall, participants responded more efficiently to positive words and there was a strong right visual field advantage. We did not find a significant interaction, however. Further analysis indicated that to find a replicable interaction between a stimulus characteristic and visual half-field, one requires much high numbers of participants and stimuli than done so far (and more than most researchers would be willing to invest). Experimental power is particularly low when the interaction is not fully crossed (a right visual field advantage for one type of stimulus and an equally large left visual field advantage for the other type of stimulus). If such investment cannot be made, the outcome is likely to be ambiguous at best and deceiving at worst if only significant findings are published.
\end{abstract}

Keywords: language, hemispheric specialization, emotion, emotion word processing, Visual Half Field, lexical decision task 
Throughout the years, researchers have been interested in whether emotion words are processed differently from neutral words. A review is given by Kuperman, Estes, Brysbaert, \& Warriner (2014), who concluded that valence and arousal exert independent effects: Negative words are recognized more slowly than positive words and arousing words are recognized more slowly than calming words. Valence explained about $2 \%$ of the variance in word recognition latencies, whereas the effect of arousal was considerably smaller (.2\% of variance). Both variables interacted with word frequency, such that valence and arousal exerted larger effects on low-frequency words than on high-frequency words.

Longer response times to negative stimuli than to neutral stimuli have often been interpreted as evidence for an automatic vigilance effect. According to this hypothesis, organisms preferentially attend to negative stimuli and these hold attention longer than other stimuli (Fox, Russo, Bowles, \& Dutton, 2001). As a consequence, participants react more slowly to negative emotional stimuli in lexical decision tasks (Wentura, Rothermund, \& Bak, 2000). The automatic vigilance hypothesis assumes that emotion affects response times at late stages, when participants make their decisions.

The automatic vigilance hypothesis does not explain why responses are faster to positive words than to neutral words. Indeed, Kuperman et al. (2014) observed that faster responses to positive words than to neutral words are consistently obtained, whereas the difference between negative and neutral words is often absent when words are properly controlled for word frequency and word length. In some studies responses to negative stimuli are even faster than to neutral stimuli (e.g., Kousta, Vinson, \& Vigliocco, 2009; Yap \& Seow, 2013).

Faster responses to emotional words than to neutral words are consistent with Lang, Bradley, and Cuthbert's (1997) model of motivated attention and affective states, which assumes that emotions are fundamentally organized around two motivational systems: 
defensive and appetitive. The former is activated in response to threats (i.e., negative stimuli), whereas the latter is active in contexts that promote survival (i.e., positive stimuli). Hence, attention is captured and sustained by motivationally relevant negative and positive stimuli, relative to neutral stimuli.

A related question is to what extent different brain halves are involved in the processing of emotional and neutral words. As is well-known, the left hemisphere is dominant for language in the vast majority of people (Ocklenburg \& Gunturkun, 2018; Vingerhoets, 2019). However, with respect to the processing of emotional stimuli, two contradictory ideas have been proposed. According to the Right Hemisphere Hypothesis (RHH), the right hemisphere is specialized for all emotion processing (Borod et al., 1998; Rodway, Wright, \& Hardie, 2003), whereas the Valence-Specific Hypothesis (VSH) states that the left hemisphere is specialized for positive emotions and the right hemisphere for negative emotions (Ahern \& Schwartz, 1979).

Killgore and Yurgelun-Todd (2007) ran a fMRI study to contrast both hypotheses. They used chimeric faces consisting of a happy and a sad half. By comparing brain activation to stimuli with the happy/sad half to the left or to the right, they concluded that the two hypotheses may not be in opposition, but may reflect different facets of a "complex distributed emotion processing system". According to this view there would be a right dominance for emotion processing, but the left hemisphere would have a larger contribution for positive stimuli than for negative stimuli (see also Butler, O'Mara, \& Wilson, 2018; Zhao et al., 2018).

Another interesting fMRI study was run by Kuchinke, Jacobs, Grubich, Vo, Conrad, and Herrmann (2005), who used single words as stimuli. All words activated a network of mainly left hemisphere brain regions, which the authors interpreted as a network for semantic word knowledge. Emotional words led to additional prefrontal and middle temporal activations. Although the negative-neutral subtraction contrast showed extra 
activation in the right frontal cortex and the positive-neutral contrast extra activation in the left frontal cortex, the authors did not consider their findings as evidence for VSH, because none of the regions survived a direct positive vs. negative comparison. Instead, Kuchinke et al. (2005) concluded that both positive and negative stimuli are processed in both hemispheres and differ from the processing of neutral words.

The issue of the laterality of emotional processing has also been addressed behaviourally. As our research concerns the processing of visually presented words, we restrict the literature review to visual half field (VHF) studies with verbal stimuli. In the VHF paradigm, words are presented to the left and to the right of fixation. Words presented in the left visual half field (LVF) are initially projected to the right hemisphere and words presented in the right visual half field (RVF) are projected to the left hemisphere. Therefore, a RVF advantage can be interpreted as left hemisphere processing superiority, whereas a LVF advantage points to right hemisphere superiority (Hunter \& Brysbaert, 2008; Van der Haegen, Cai, Seurinck, \& Brysbaert, 2011). By comparing VHF asymmetries for different types of words, researchers can examine different laterality patterns. We found eight studies on the topic of emotion summarized in Table 1.

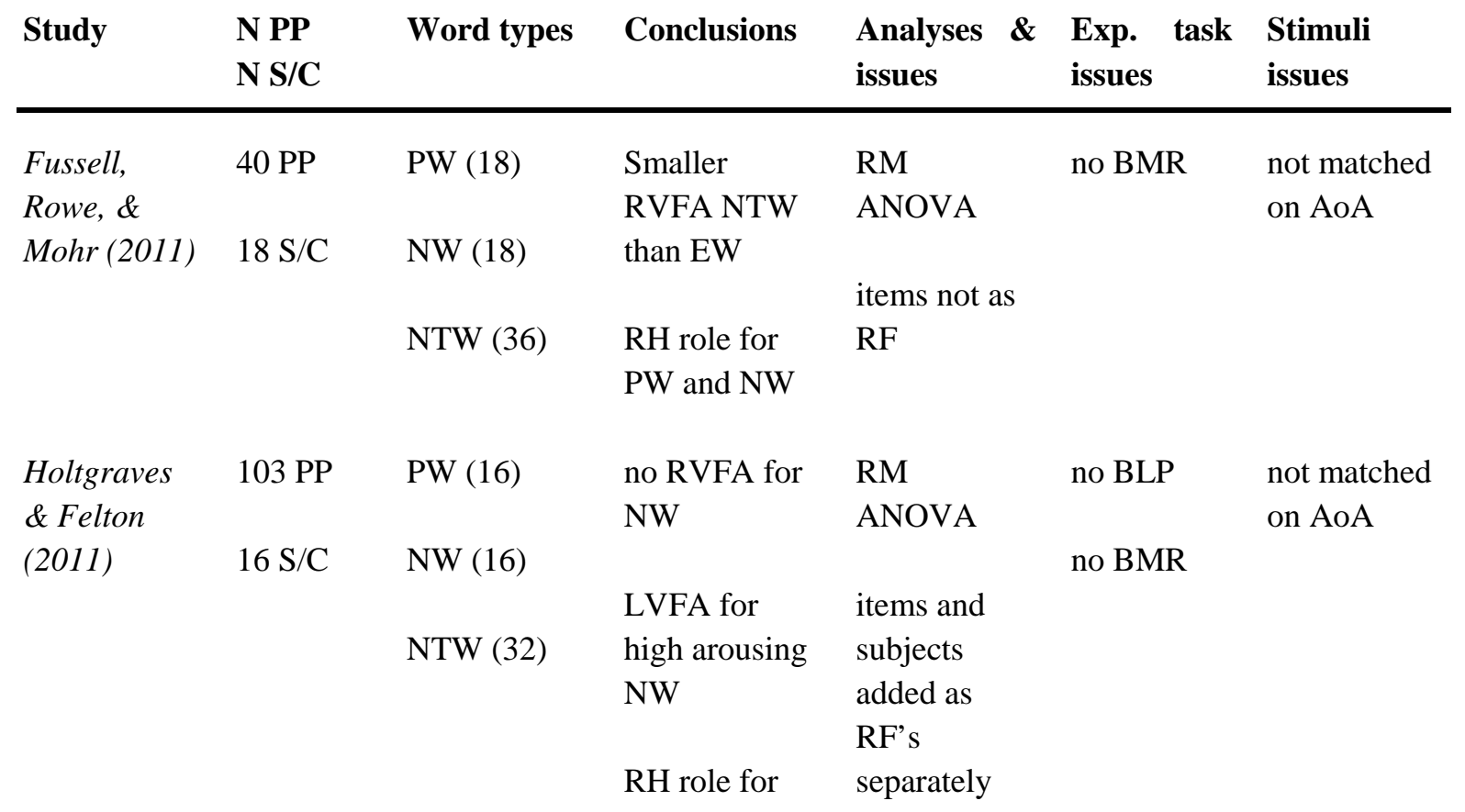




\begin{tabular}{|c|c|c|c|c|c|c|}
\hline & & & NW & & & \\
\hline \multirow[t]{5}{*}{$\begin{array}{l}\text { Jónczyk } \\
\text { (2015) }\end{array}$} & $68 \mathrm{PP}$ & PW (12) & \multirow[t]{2}{*}{$\begin{array}{l}\text { RVFA for all } \\
\text { words }\end{array}$} & \multirow[t]{2}{*}{$\begin{array}{l}\text { RM } \\
\text { ANOVA }\end{array}$} & no BLP & \multirow[t]{2}{*}{$\begin{array}{l}\text { not matched } \\
\text { on AoA }\end{array}$} \\
\hline & \multirow[t]{4}{*}{$12 \mathrm{~S} / \mathrm{C}$} & NW (12) & & & \multirow[t]{4}{*}{ no BMR } & \\
\hline & & & even stronger & items not as & & \\
\hline & & NTW (12) & RVFA for EW & $\mathrm{RF}$ & & \\
\hline & & & $\begin{array}{l}\text { no } \mathrm{RH} \text { role for } \\
\text { EW }\end{array}$ & & & \\
\hline \multirow[t]{5}{*}{$\begin{array}{l}\text { Kanske \& } \\
\text { Kotz (2007) }\end{array}$} & $60 \mathrm{PP}$ & $\begin{array}{l}\text { PW }(30 \\
\text { concrete, } 30\end{array}$ & $\begin{array}{l}\text { RVFA for all } \\
\text { words }\end{array}$ & $\begin{array}{l}\text { RM } \\
\text { ANOVA }\end{array}$ & no BLP & \multirow[t]{4}{*}{$\begin{array}{l}\text { not matched } \\
\text { on AoA }\end{array}$} \\
\hline & \multirow[t]{4}{*}{$30 \mathrm{~S} / \mathrm{C}$} & abstract) & & & \multirow[t]{3}{*}{ no BMR } & \\
\hline & & & even stronger & items not as & & \\
\hline & & NW $(30,30)$ & RVFA for EW & $\mathrm{RF}$ & & \\
\hline & & NTW $(30,30)$ & $\begin{array}{l}\text { no } \mathrm{RH} \text { role for } \\
\text { EW }\end{array}$ & & & \\
\hline \multirow{4}{*}{$\begin{array}{l}\text { Kuruoglu \& } \\
\text { Mergen } \\
(2016)\end{array}$} & $48 \mathrm{PP}$ & PW (10) & \multirow[t]{2}{*}{$\begin{array}{l}\text { RVFA for all } \\
\text { words }\end{array}$} & \multirow{4}{*}{$\begin{array}{l}\text { no } \\
\text { information } \\
\text { on which } \\
\text { analysis was } \\
\text { used (SPSS) }\end{array}$} & no BLP & \multirow[t]{4}{*}{$\begin{array}{l}\text { not matched } \\
\text { on AoA }\end{array}$} \\
\hline & $10 \mathrm{~S} / \mathrm{C}$ & NW (10) & & & no BMR & \\
\hline & & & no $\mathrm{RH}$ role for & & & \\
\hline & & NTW (10) & EW & & & \\
\hline \multirow{4}{*}{$\begin{array}{l}\text { Martin \& } \\
\text { Altarriba } \\
(2017)\end{array}$} & $85 \mathrm{PP}$ & \multirow{4}{*}{$\begin{array}{l}\text { PW (10 } \\
\text { emotion- } \\
\text { labelled, } 10 \text { - } \\
\text { laden) } \\
\text { NW (10,10) } \\
\text { NTW (10) }\end{array}$} & $\begin{array}{l}\text { no RVFA for } \\
\text { NW }\end{array}$ & $\begin{array}{l}\text { classical } \\
\text { mixed }\end{array}$ & no BLP & \multirow[t]{4}{*}{$\begin{array}{l}\text { not matched } \\
\text { on AoA }\end{array}$} \\
\hline & $10 \mathrm{~S} / \mathrm{C}$ & & $\mathrm{RH}$ role for & ANOVA & no BMR & \\
\hline & & & NW & items not as & & \\
\hline & & & & $\mathrm{RF}$ & & \\
\hline \multirow[t]{4}{*}{$\begin{array}{l}\text { Mohr et al. } \\
(2005)\end{array}$} & $22 \mathrm{PP}$ & EW (8) & $\begin{array}{l}\text { males: no } \\
\text { RVFA for EW }\end{array}$ & $\begin{array}{l}\text { RM } \\
\text { ANOVA }\end{array}$ & \multirow[t]{4}{*}{ no BMR } & $\begin{array}{l}\text { not matched } \\
\text { on AoA }\end{array}$ \\
\hline & $8 \mathrm{~S} / \mathrm{C}$ & NTW (8) & & & & \\
\hline & & & RH role for & items not as & & \\
\hline & & & EW & $\mathrm{RF}$ & & \\
\hline $\begin{array}{l}\text { Mohr, Rowe } \\
\& \text { Crawford }\end{array}$ & $50 \mathrm{PP}$ & $\begin{array}{l}10 \text { anxiety } \\
\text { words }\end{array}$ & $\begin{array}{l}\text { smaller RVFA } \\
\text { for PW }\end{array}$ & $\begin{array}{l}\text { RM } \\
\text { ANOVA }\end{array}$ & no BMR & not matched \\
\hline$(2008)$ & $10 \mathrm{~S} / \mathrm{C}$ & & & items not as & & \\
\hline & & 10 avoidance & $\begin{array}{l}\text { RH role for } \\
\text { PW }\end{array}$ & $\mathrm{RF}$ & & \\
\hline & & 10 security & & & & \\
\hline
\end{tabular}

Table 1. Summary table on research of the past 2 decades on the lateralization of single emotion word stimuli using the VHF paradigm. N PP= number of participants, $\mathrm{N} \mathrm{S/C}=$ number of stimuli per condition, $\mathrm{PW}=$ positive words, $\mathrm{NW}=$ negative words, $\mathrm{NTW}=$ neutral words, $\mathrm{EW}=$ emotion words, $\mathrm{L}(\mathrm{R}) \mathrm{VFA}=$ left (right) visual field advantage, $\mathrm{R}(\mathrm{L}) \mathrm{H}=$ right (left) hemisphere, $\mathrm{RF}=$ 
random factor, $\mathrm{RM}$ ANOVA= repeated measures $\mathrm{ANOVA}, \mathrm{BMR}=$ bimanual responses, $\mathrm{BLP}=$ bilateral presentation, $\mathrm{AoA}=$ age of acquisition

Mohr et al. (2005) reported an overall RVF advantage for the accuracy with which briefly presented neutral and emotional words could be identified. However, a subgroup of men showed no VHF advantage for emotional words, in line with a right hemisphere involvement in the processing of these words. Mohr, Rowe, and Crawford (2008) ran a follow-up study with words referring to anxious, avoidant and secure situations. A RVF advantage was found for anxious and avoidant words, but not for secure words. The findings were opposite to the predictions of VSH and were interpreted as evidence for a specific role of the right hemisphere in dealing with positive interpersonal relationship information. Mohr and colleagues ran a third experiment on the topic (Fussell, Rowe, \& Mohr, 2011). Previously married and currently married individuals from a community sample were compared on the accuracy with which they could identify briefly presented neutral, positive and negative words. The authors found an overall RVF advantage, but there was a significant interaction between VHF and type of word, which was interpreted as evidence that positive attachment words yield a processing advantage over neutral words in the right hemisphere, while emotional words (irrespective of valence) yield a processing advantage over neutral words in the left hemisphere.

Kanske and Kotz (2007) reported an overall RVF advantage for emotional and neutral words and concluded that their data did not support a specific right hemisphere involvement in the processing of emotional words. Holtgraves and Felton (2011) also reported an overall RVF advantage for the recognition of words, but the interaction between type of word and VHF indicated a deviating pattern for negative words, in particular highly arousing negative words, which showed a LVF advantage, in line with VSH predictions. A smaller RVF advantage for negative words than for positive and 
neutral words was also reported by Martin and Altarriba (2017), but not by Jończyk (2015) who found a smaller RVF advantage for neutral words than for positive and negative words. Martin and Altarriba (2017) further compared emotion-labelled words (words that refer to positive or negative emotions, e.g. joy or aggression) and emotion-laden words (words that carry a positive or negative connotation, e.g. flower or weapon), but found no differences between them. Jończyk (2015) tested Polish-English bilinguals in their second language (English), which may have been an important factor, as Kuruoglu and Mergen (2016) observed that Turkish monolinguals showed a significant RVF advantage for emotion words (both positive and negative), whereas Turkish-English bilinguals did not show such an advantage.

All in all, a rather confusing and contradictory picture emerges from the VHF literature review. One reason for this is arguably the small number of observations per condition. On the basis of simulation, Brysbaert and Stevens (2018) recommended that at least 1,600 observations be included per condition (e.g. 40 stimuli, 40 participants) to have a properly powered reaction time experiment. As can be seen in Table 1, only Kanske \& Kotz (2007) and Holtgraves and Felton (2011) reached this number.

A second problem with the available evidence is that only one study (Holtgraves \& Felton, 2011) verified whether the findings generalized across stimuli. In all other studies, mean performance per condition per participant was used in the statistical analysis. This is a problem, because the difference between conditions could be due to one or two deviating stimuli (Brysbaert, 2020, Chapter 17). If researchers want to compare different groups of stimuli, they must include stimuli as a random factor in their design in addition to participants (see below).

Next to the above two problems, we had some further concerns about the available evidence. First, the majority of the studies did not match their stimuli on age of acquisition, 
although this is known to be an important factor in word recognition. Early acquired words are processed more efficiently than late acquire words (Brysbaert, Stevens, Mandera, \& Keuleers, 2016; Juhasz, 2005). Second, stimulus presentation was mostly unilateral (either in LVF or RVF). More stable results are obtained with bilateral presentation (Hunter \& Brysbaert, 2008), because then the stimulus onset does not create a shift in attention. Finally, participants mostly had to press buttons with the left or the right hand, which creates the danger of a stimulus-response compatibility effect (responses with the right hand are faster to stimuli in RVF and responses with the left hand are faster to stimuli in LVF; Berlucchi, Crea, di Stefano, \& Tassinari, 1977). Therefore, bimanual responses should be used.

To address the inconsistent results in Table 1, we decided to run a new VHF study addressing the various shortcomings we identified. We hypothesized first that all words would be processed more rapidly in RVF than in LVF, because language is strongly centred in the left hemisphere and because there are other factors favouring word processing in RVF for languages read from left to right (Brysbaert \& Nazir, 2005). Second we expected that positive words would be processed more rapidly than neutral words, and negative words would be processed most slowly, in line with the results of Kuperman et al. (2014). Finally, we aimed to contrast the Right Hemisphere Hypothesis (RHH) and the Valence- Specific Hypothesis (VSH) by looking for an interaction between valence and VHF. A smaller VHF difference for emotion words would be in line with RHH; a smaller VHF difference for negative words only would be in line with VSH.

\section{Method}

\section{Participants}

An initial sample of 40 (27 female) psychology students ( $1^{\text {st }}$ Bachelor, range $18-20$ years of age) from the University of Ghent (Belgium) was included. However, data from one 
participant had to be removed because of inadequate Dutch knowledge. The other 39 participants were native Dutch speakers. Participants were all right-handed, as left-handed individuals have a higher chance of non- typical language dominance (Szaflarski et al., 2012). Participants were asked to sign an informed consent.

\section{Stimuli}

Three types of words were used, based on their valence: positive, negative and neutral words. Fifty words per type were chosen from the Dutch Lexicon Project 2 (Brysbaert et al., 2016), a dataset containing over 30,000 Dutch words. In this dataset, information about the length of the words (number of syllables and phonemes), age of acquisition, prevalence, concreteness, similarity to other words (OLD20) and frequency is available, so that we could match our words on these variables. As the Dutch Lexicon Project 2 does not include valence and arousal, we made use of Moors et al. (2013), who collected norms for valence and arousal for 4300 Dutch words. These norms are based on ratings with a 7-point Likert scale $(1=$ very negative/unpleasant, $2=$ fairly negative/unpleasant, $3=$ somewhat negative/unpleasant, $4=$ neutral, $5=$ somewhat positive/pleasant, $6=$ fairly positive/pleasant, $7=$ very positive/pleasant) from four independent samples (two Belgian, two Dutch). Means were measured across all participants and the norms had a high reliability. In the current study, negative emotion words had a rating equal to or lower than 2.5 , positive emotion words were equal to or higher than 5.5, and neutral words were between 3.5 and 4.5. The mean valence for positive words was $6.04(\mathrm{sd}=0.24)$, for negative words it was $1.86(\mathrm{sd}=0.30)$, and for neutral words $4.07(\mathrm{sd}=0.21)$.

Arousal was matched for the positive and negative words. Arousal of the neutral words was lower, in line with the V-shaped function between valence and arousal. According to Kuperman et al. (2014) this slightly favoured the neutral words, but the effect is only one tenth of the effect expected from valence. It did not seem indicated to try to match the neutral 
words on arousal, as there is an inherent relationship between valence and arousal:Emotion words are more arousing than neutral words.

Finally, we were unable to fully match the stimuli on concreteness. We checked for this by running extra analyses post hoc. We did not find any evidence that the variable had an effect on our results, in line with the observation of Brysbaert et al. (2016) that concreteness has no effect anymore once the other variables are controlled for.

An overview of the means and standard deviations for our matched variables is presented in Table 2. The full stimulus set is given in the Appendix.

\begin{tabular}{lccc} 
& Positive & Negative & Neutral \\
\hline Valence & $6.04(0.24)$ & $1.85(0.30)$ & $4.07(0.21)$ \\
Arousal & $4.75(0.77)$ & $4.70(1.16)$ & $3.97(0.68)$ \\
N Letters & $5.28(0.97)$ & $5.28(0.97)$ & $5.28(0.97)$ \\
N Syllables & $1.58(0.50)$ & $1.58(0.50)$ & $1.58(0.50)$ \\
Age of Acquisition & $6.60(1.88)$ & $6.84(1.73)$ & $6.64(1.63)$ \\
Log Frequency & $3.14(0.74)$ & $3.08(0.62)$ & $3.00(0.66)$ \\
Concreteness & $2.29(0.69)$ & $3.10(0.74)$ & $3.37(0.99)$ \\
Prevalence & $2.72(0.29)$ & $2.59(0.37)$ & $2.71(0.29)$ \\
Similarity (OLD20) & $1.62(0.39)$ & $1.52(0.41)$ & $1.52(0.41)$ \\
\hline
\end{tabular}

Table 2. Descriptive statistics for possible confounding variables for positive, negative and neutral words. All variables are matched, except for arousal and concreteness. Post-hoc analyses revealed no influence of concreteness on our results. There is an inherent relation between valence and arousal (positive and negative words are more arousing than neutral words). For a full description of the variables and their influence on visual word recognition, see Brysbaert et al. (2016). 


\section{Procedure}

Participants were welcomed by the experimenter and directed to a separate, soundproof room. They took place in front of a computer screen (distance of about $50 \mathrm{~cm}$ ) and were encouraged to keep their head still. The experiment started with a practice block of 50 trials, followed by six experimental blocks of 100 trials each, with short breaks between the blocks. There were 600 trials because words and nonwords were presented once in LVF and once in RVF, to make sure that the VHF differences were not influenced by the distribution of words across VHFs (Hunter \& Brysbaert, 2008). Each participant got a different, random permutation of the 600 test trials.

On each trial, a fixation cross appeared first in the centre of the screen for $600 \mathrm{~ms}$. After that, a central arrow (sized 1 degree of visual angle) appeared together with a word in LVF or RVF and a neutral stimulus of the same length (e.g. \#\#\#\#) in the other VHF. The arrow pointed to the word the participants had to respond to. The purpose of the neutral stimuli was to make sure that bilateral presentation was fulfilled (Hunter \& Brysbaert, 2008). The stimuli disappeared after $200 \mathrm{~ms}$, as research has indicated that participants cannot initiate an eye movement within $200 \mathrm{~ms}$ when they first have to pay attention to a stimulus at the fixation location (Walker \& McSorley, 2006). Finally, a backward mask was presented for $200 \mathrm{~ms}$. The target words were presented in Arial font 14. The distance from the fixation cross to the middle of the target words or the neutral stimuli was 2 visual degrees. The height of ascender in the word was $0.6^{\circ}$ visual angle, the width was then determined by the font (Arial 14) and the number/width of the letters in the word (range 4-7 letters: $1.7-2.4^{\circ}$ ). This presentation method has been shown to result in a right visual field advantage for individuals with left hemisphere language dominance and in a left visual field advantage for individuals with right hemisphere dominance (Van der Haegen et al., 201). An example of a trial is shown in Figure 1. 


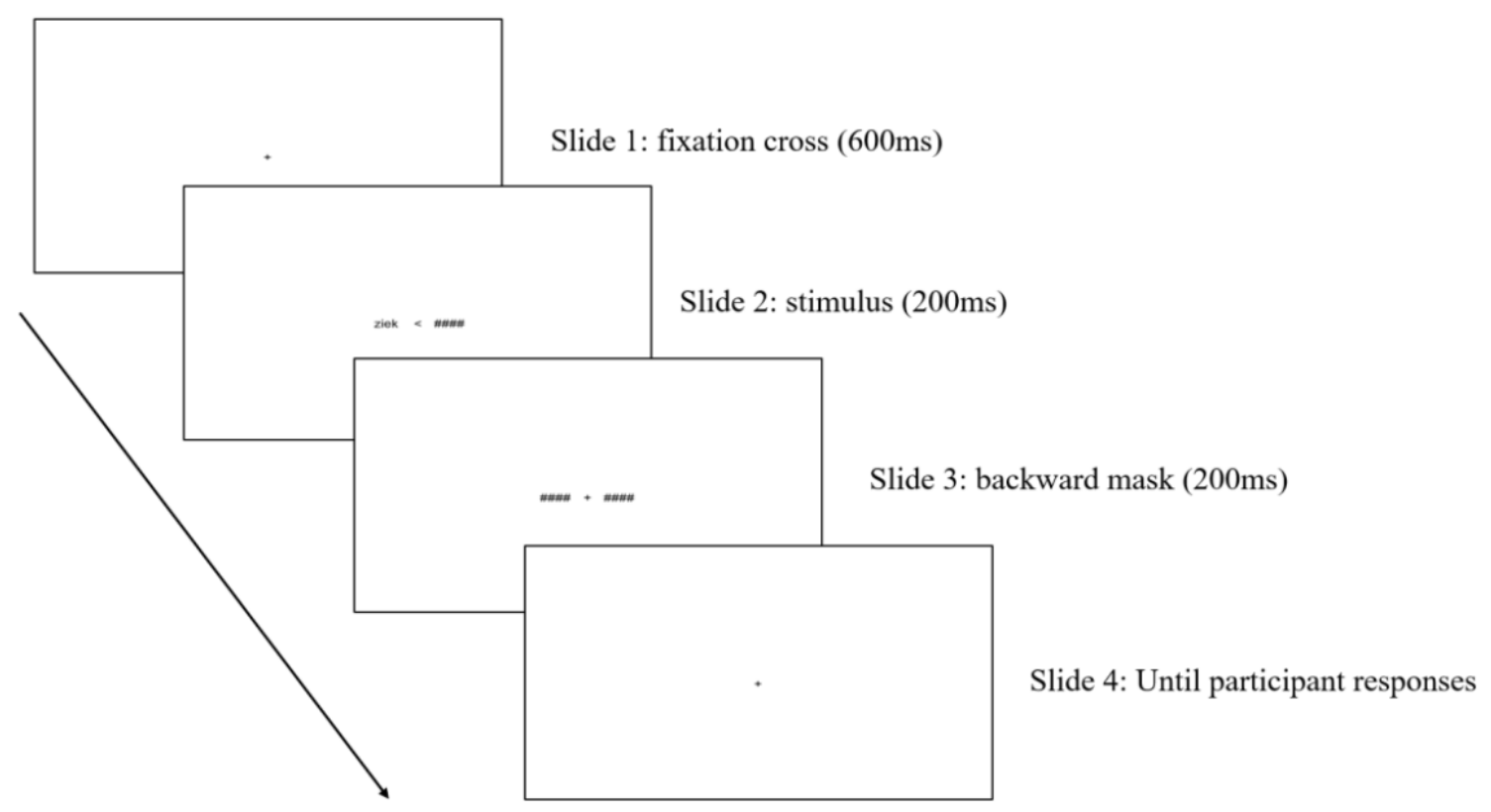

Figure 1. Visualization of the experimental procedure. Inner distance of words from the fixation cross were $2^{\circ}$ visual angle, width around $3.43^{\circ}$ visual angle. Here, the correct answer is 'word', as 'wapen' is an existing Dutch word, meaning 'weapon'. The participant should press with both index fingers, because the word is an actual word. This is an example of a negative emotionword.

For the responses, we made use of a Cedrus Response Box. Four keys were available to the participants in an ergonomic format (outer keys higher than middle keys). They had to keep their hands with the index fingers on the lower keys, and the middle fingers on the higher keys. The Cedrus Response Box measures responses with millisecond accuracy. If participants decided the stimulus they just saw was an existing word, they had to press with both index fingers. If the word was a pseudoword, they had to press with both middle fingers. The fixation cross of the next trial appeared immediately after the participant made their decision and the reaction time was recorded. 


\section{Results}

The summary data are shown in Table 3 .

\begin{tabular}{lllll}
\hline & & & & \\
\hline \multirow{2}{*}{ Mean } & valence & VHF & RT (SD) & Acc (SD) \\
& \multirow{6}{*}{ Neg } & left & $809(203)$ & $82 \%(.08)$ \\
& & right & $764(175)$ & $93 \%(.07)$ \\
& \multirow{6}{*}{ Neutr } & left & $814(199)$ & $78 \%(.09)$ \\
& & right & $767(170)$ & $89 \%(.08)$ \\
& \multirow{2}{*}{ Pos } & left & $788(195)$ & $84 \%(.08)$ \\
& & right & $755(173)$ & $92 \%(.05)$
\end{tabular}

Table 3. RTs and accuracy as a function of Valence and VHF (SDs between brackets)

\section{Reaction Time Analysis}

Reaction times were measured from the onset of the stimulus until the participants' response. The data from the 39 participants were cleared for outliers; all trials with reaction times below $200 \mathrm{~ms}$ and above $1500 \mathrm{~ms}$ were removed before any analysis was run (2.9\% data loss). Only reaction times (RTs) of correct responses to words were included in the analysis. Table 3 shows the results.

To compare our results to those published, a 3 (valence: negative, positive, neutral) $\mathrm{x} 2$ (VHF: RVF, LVF) repeated measures ANOVA was run. This resulted in a main effect of VHF due to faster $\mathrm{RVF}$ responses $(\mathrm{LVF}=804 \mathrm{~ms} ; \mathrm{RVF}=762 \mathrm{~ms} ; \mathrm{F}(1,38)=32,71, \mathrm{MSE}=$ $2754, \mathrm{p}<.001$ ) and a main effect of Valence due to faster responses to positive words (Pos $=771 \mathrm{~ms}, \mathrm{Neg}=786 \mathrm{~ms}, \mathrm{Neu}=791 \mathrm{~ms} ; \mathrm{F}(2,76)=7.38, \mathrm{MSE}=767, \mathrm{p}=.001)$. There was no significant interaction $(F(2,76)=1.44, \operatorname{MSE}=590, \mathrm{p}=.244)$.

The ANOVA with participants as the only random variable assumes that we are only interested in the stimuli tested and that we do not want to generalize to other words. In principle, all differences between the valence conditions could be due to one positive word responded to much faster than all other words (Brysbaert, 2020, Chapter 17). To test which effects survived an analysis with both participants and word stimuli as random effects, we ran 
an additional mixed-effects analysis using the R package lme4 (Bates, Mächler, Bolker, \& Walker, 2014). We used the full model, defined as:

fit $1<-\operatorname{lmer}\left(\mathrm{RT} \sim \mathrm{VHF}^{*}\right.$ valence + $\left(\mathrm{VHF}^{*}\right.$ valence|items $)+\left(\mathrm{VHF}^{*}\right.$ valence|subject $), \mathrm{REML}$ $=\mathrm{F}$, data $=$ data_W_correct $)^{1}$

This analysis confirmed the reliable main effect of VHF $(t=5.34)$ and indicated that responses to the positive stimuli were somewhat faster than responses to the neutral $(\mathrm{t}=2.0)$ or to the negative stimulus $(\mathrm{t}=1.9)$. Given that the $\mathrm{t}$-values are close to 2 , they signal differences of potential interest $(\mathrm{p}<.05)$. There was no evidence for a difference between neutral and negative items $(\mathrm{t}=.3)$. Again, there was no indication of a significant interaction between VHF and Valence. The latter was tested by comparing the model with interaction to a model without interaction, defined as:

fit2 <- $\operatorname{lmer}(\mathrm{RT} \sim \mathrm{VHF}+$ valence $+(\mathrm{VHF}+$ valence|items $)+(\mathrm{VHF}+$ valence|subject $), \mathrm{REML}$ $=\mathrm{F}$, data $=$ data_W_correct $)$

anova(fit1,fit2)

The difference between both models was not significant: $\operatorname{chisq}(\mathrm{df}=24)=18.53, \mathrm{p}=$ .78 , indicating that the model without interaction fitted the data as well as the model with the interaction. Actually, it fitted the data slightly better as the Akaike information criterion of the model without interaction $($ AIC $=125654)$ was lower than that of the model with the interaction $(\mathrm{AIC}=125684)$, due to the smaller number of parameters that had to be estimated. Interestingly, in the model without interaction, the difference between positive and neutral/negative words was no longer significant $(\mathrm{t} \approx 1.4)$.

\section{Accuracy Analysis}

To ensure that the RT differences were not overshadowed by contradictory differences in accuracy levels, we ran similar analyses on the accuracy data. For the ANOVA with

\footnotetext{
${ }^{1}$ REML $=\mathrm{F}$ had to be included to compare models. Extra analyses indicated that the results we report are valid both for models estimated with REML (restricted maximum likelihood) and ML (maximum likelihood).
} 
participants as the sole random factor, we used a 3 (valence: negative, positive, neutral) x 2 (VHF: RVF, LVF) repeated measures ANOVA with mean accuracy on the word trials per condition per participant as the dependent variable. The accuracy data of the non-words were excluded from the analysis.

The ANOVA returned a significant main effect of VHF $(\mathrm{LVF}=82 \%, \mathrm{RVF}=91 \%$; $\mathrm{F}(1,38)=58.52, \mathrm{MSE}=.0098 \mathrm{p}<0.001)$, a main effect of valence because accuracy was lower for the neutral words $(\operatorname{pos}=88 \%$, neg $=88 \%$, neutral $=84 \% ; \mathrm{F}(2,76)=24.92, \mathrm{MSE}=.0019$, $\mathrm{p}<.001)$, and the possibility of an interaction $(\mathrm{F}(2,76)=3.21, \mathrm{MSE}=.0023, \mathrm{p}=.046)$.

To examine which of these effects generalize to different stimulus sets, a mixedeffects analysis was run with both participants and stimuli as random factors. As the effect concerns yes/no accuracy data, a binomial function was used:

fit $1<-$ glmer(accuracy $\sim$ VHF*valence + (VHF*valence|items $)+($ VHF*valence|subject $)$, data $=$ data_W_all, family="binomial")

The analysis confirmed the clear RVF advantage $(t=6.9)$ and the fact that neutral words were responded to less accurately (comparison with positive words: $\mathrm{t}=3.2$; comparison to negative words: $\mathrm{t}=2.3$ ). There was no indication for a significant interaction. The latter was checked by comparing the previous model to a model without interaction:

fit2 <- glmer(accuracy $\sim$ VHF+valence + (VHF+valence|items $)+(\mathrm{VHF}+$ valence|subject $)$, data = data_W_all, family="binomial")

anova(fit1,fit2)

The model with the interaction did not fit the data better than the model without the interaction $(\operatorname{Chisq}(\mathrm{df}=24)=16.1, \mathrm{p}=.89)$. If anything, the model without interaction gave a better fit $(\mathrm{AIC}=7895)$ than the model with interaction $(\mathrm{AIC}=7927)$ because it needed fewer parameters to be estimated. In this analysis, the worse performance on neutral 
stimuli remained significant ( $\mathrm{t}$ for the comparison with positive stimuli $=3.0$; $\mathrm{t}$ for the comparison with negative stimuli $=2.2$ ).

The main conclusion of the accuracy analysis is that accuracy is in line with RT, so that we can interpret the RT differences without having to worry about speed-accuracy trade-offs.

\section{Discussion}

The current study investigated the influence of valence (positive, negative, neutral) on the RVF advantage for word recognition. Previous studies had returned conflicting evidence, summarized in Table 1. While some researchers found results in line with the ValenceSpecific Hypothesis (Holtgraves \& Felton, 2011; Martin \& Altarriba, 2017), others found patterns suggesting no difference in processing between emotional and neutral words (Kanske \& Kotz, 2007) or found interactions between VHF and word type that suggested other laterality configurations (Fussell et al., 2011; Jończyk, 2015; Kuruoglu \& Mergen, 2016; Mohr et al., 2005, 2008).

At first sight, our data further complicate the picture because we obtained no differences in RVF advantage between the three types of stimuli (in line with Kanske \& Kotz, 2007). Furthermore, in our study positive words were responded to more rapidly (771 ms) than negative $(786 \mathrm{~ms})$ and neutral words $(791 \mathrm{~ms})$. This contrasts with Jończyk (2015) who obtained faster responses to negative stimuli (426 ms) than to positive (444 ms) and neutral stimuli (448 ms). Faster responses to positive words than to neutral words are expected on the basis of a large-scale word analysis (Kuperman et al., 2014) and were indeed reported in most studies ${ }^{2}$ (Fussell et al. 2012: 532 vs. 557 ms; Holtgraves \& Felton, 2011: 672 vs. 699 ms; Kanske \& Kotz, 2007: 543 vs. 586 ms; Martin \& Altarriba, 2017:

\footnotetext{
${ }^{2}$ Kuruoglu \& Mergen (2016) did not report performance for neutral stimuli but the positive words were responded to more rapidly than the negative words. Mohr et al. $(2005,2008)$ did not contain all conditions.
} 
745 vs. $773 \mathrm{~ms}$ ). Also in line with the large-scale word analysis, the position of negative words is more variable, sometimes in-between positive and neutral words (present study; Holtgraves \& Felton, 2011; Kanske \& Kotz, 2007), sometimes below the other two conditions (Fussell et al., 2012; Jończyk, 2015), and sometimes above the other conditions (Martin \& Altarriba, 2017).

The findings become less contradictory when we take into account that we have to include stimuli as a random variable as well, if we want to generalize to the populations of positive, negative and neutral stimuli. If we do not do this, we assume that the few words we included in the study represent the full population of interesting words. This misunderstanding is called the "language-as-a-fixed-effect fallacy" (Clark, 1973). When variability between items is not taken into consideration, one or two items with fast or slow response times can drive the differences between conditions because the analysis is entirely based on averages over items (see Brysbaert, 2020, Chapter 17, for a more detailed discussion). When we add stimuli as a random variable, the valence differences we observed were largely compatible with stimulus variability within the conditions. Arguably the same was true for the other studies, given the small number of stimuli they included per condition.

Kuperman et al. (2014) argued that researchers have to study thousands of words if they want to have a clear picture of the ways in which valence influences word processing. In addition, they showed that the effects are most pronounced for low-frequency words, which cannot be used in VHF research, because participants are unable to recognize them when they are presented briefly in peripheral vision (remember that the words were presented for $200 \mathrm{~ms}$ in parafoveal vision). Kuperman et al.'s (2014) findings agree with the small valence effect we obtained (at most $20 \mathrm{~ms}$ difference). A further agreement is that in both studies positive words were the easiest to process. A deviation was that Kuperman et al. (2014) concluded that negative words were the slowest to respond to. However, this conclusion was only true after they 
partialled out the interaction between valence and word frequency (a situation we tried to simulate by matching the words on frequency and other variables). In their raw data there was a drop in RT for very negative words (see their Figure 2). Clearly, more research (based on very large stimulus sets) is needed to have a more trustworthy picture of the difference between negative and neutral words.

Given that valence-related differences in lexical decision RTs are $20 \mathrm{~ms}$ at most, we cannot expect to find very large RT differences in VHF asymmetries. For all words we expected a reliable RVF advantage (as we indeed found; there was an overall difference of $42 \mathrm{~ms}$ ). If the effect of valence was entirely due to a single hemisphere, we would expect a RVF advantage of at most $20 \mathrm{~ms}$ extra for stimuli processed in the left hemisphere (i.e., 64 ms) and an RVF advantage of at most $20 \mathrm{~ms}$ less for stimuli processed in the right hemisphere (24 ms). Such a situation is unlikely to arise in reality, however, for two reasons. The first reason is that visual word processing involves interactions with phonological information, so that there is a strong push to process visually presented words in the hemisphere with the speech centre (usually the left hemisphere). Indeed, interhemispheric transfer from the non- language-dominant to the dominant hemisphere has been documented at the very first stages of visual word processing, in the occipital cortex and in the border region between the occipital and temporal cortex (Strother, Zhou, Coros, \& Vilis, 2017; Van der Haegen, Cai, \& Brysbaert, 2012). Although feedback from the frontal cortex is known to influence visual word processing up to the occipital cortex (Price \& Devlin, 2011), it is unlikely that feedback from emotional brain centres could completely alter the information flow.

The second reason why the effect of emotionality on VHF asymmetries is likely to be less than maximal is that the processing of emotions depends on brain networks that are less lateralized than assumed by the right hemisphere hypothesis and the Valence-Specific Hypothesis (Fusar-Poli et al., 2009; Kuchinke et al., 2005; Lindquist, Wager, Kober, Bliss- 
Moreau, \& Barrett, 2012; Wager, Phan, Liberzon, \& Taylor, 2003). In this respect, it is important to keep in mind that lexical decision times are a crude measure because they only provide information about the total time needed for a complex process with several interactive components.

If the to-be-expected effect of emotionality on VHF asymmetries is only in the order of 5-20 ms, this has serious consequences for the number of observations required to detect the effect reliably. On the basis of simulation, Brysbaert and Stevens (2018) recommended a minimum of 40 participants and 40 stimuli per condition to find an RT difference of 16 ms in lexical decision time, which we used as a guideline to set up our study. However, these numbers were based on a comparison of two repeated-measures conditions. If the experiment involves a manipulation between stimuli (as was the case for valence in the present study), Keuleers, Lacey, Rastle and Brysbaert (2012) observed that 160 stimuli per condition were required to find a difference of $20 \mathrm{~ms}$ in lexical decision times with $80 \%$ power.

The requirements are still higher when the research involves the assessment of an interaction rather than a main effect. Only in case of a fully crossed interaction do the numbers of observations required for a main effect suffice (Brysbaert, 2019; Perugini, Gallucci, \& Costantini, 2018). That is a situation in which one type of stimulus elicits a reliable RVF advantage and the other type of stimulus elicits an equally strong LVF advantage. In the more likely situation of no VHF asymmetry for one type of stimulus and a reliable VHF asymmetry for the other type of stimulus, the number of participants required must be multiplied by four (i.e., a total of at least 160 participants). The number further increases if the VHF asymmetry for one type of stimulus is just a bit smaller than that for the other type (Perugini et al., 2018).

The above numbers shine a new light on the findings of our study (and the studies mentioned in Table 1). Although our results did not provide evidence for an interaction 
between VHF and valence, we must admit that we did not have the a priori power to find a difference of 5-20 ms in visual asymmetry for one or two of the valence conditions (as predicted by respectively the Valence-Specific Hypothesis and the Right Hemisphere Hypothesis). A rough count indicates that we should have had at least 160 participants and three groups of 160 words presented twice (once in LVF and once in RVF). ${ }^{3}$ That is a total of 1920 test observations per participants (of which half are lost because of the nonword trials) or a total of 307,200 observations for the complete experiment. ${ }^{4}$

Underpowered studies are a particular problem in a context with high rejection rate and publication bias, where significant results have a higher probability of being published than null findings (Fanelli, 2011; Ferguson \& Heene, 2012; Franco, Malhotra, \& Simonovits, 2014). What happens then is that the few studies that get published have significant effects that are impossible to replicate and often contradict each other (as seems to be the case in Table 1). We think that VHF studies are prone to such a danger, in particular those studies that involve an interaction between stimulus type and VHF. Indeed, in a large-scale replication study Brederoo, Nieuwenstein, Cornelissen and Lorist (2019) were able to replicate all four VHF studies with a simple main effect (involving face similarity, face emotionality, the landmark task and lexical decision), but failed to replicated nine out of eleven effects involving an interaction between VHF and stimulus features, even though most of the predictions involved crossed interactions (LVF advantage for one type of stimulus, RVF advantage for another type).

More in general, on the basis of our findings and our subsequent analyses we want to warn colleagues against running VHF experiments in which features of stimuli are manipulated for which limited effects on VHF asymmetries are expected. The dependent variables (RT and accuracy) are very crude and interactions require many observations to be

\footnotetext{
${ }^{3}$ See Vasilev, Yates, \& Slattery (2019) for a similar conclusion in a related domain.

${ }^{4}$ For comparison, our study included $39 * 150 * 2 * 2=23,400$ test observations, of which half could not be used because they were responses to nonwords.
} 
reliable and replicable. Unless one has the means (and the desire) to run such a study, the outcome is likely to be uninformative at best and deceiving at worst in a context of high rejection rate and publication bias. More information may be obtained from brain imaging data, because these give a more detailed picture, although here too issues of power and replicability must be taken into account (Button et al., 2013; Ramus, Altarelli, Zhao, \& Di Covella, 2018).

In summary, we failed to find significant differences in VHF asymmetries between positive, negative and neutral words that were matched on variables known to influence visual word recognition. As such, we were unable to replicate previous findings reported in Table 1. Further analysis revealed why our replication failed. Part of the problem is that VHF studies up to now have rarely addressed the problem of language-as-a-fixed- effect fallacy, so that differences between stimulus types looked bigger than they were, given stimulus variability. Another reason is that the effect on VHF asymmetry is likely to be small, so that unambiguous results can only be obtained if researchers are willing to collect many more observations than they have done so far.

\section{Open science}

The files with the raw data and the $\mathrm{R}$ file used for analysis are available at https://osf.io/jzqac/. 


\section{References}

Ahern, G., \& Schwartz, G. (1979). Differential lateralization for positive versus negative emotion. Neuropsychologia, 23(6), 693-698.

Bates, D., Mächler, M., Bolker, B., \& Walker, S. (2014). Fitting linear mixed-effects models using lme4. Journal of Statistical Software, 67(1), 1-48 .

Berlucchi, G., Crea, F., di Stefano, M., \& Tassinari, G. (1977). Influence of spatial stimulus-response compatibility on reaction time of ipsilateral and contralateral hand to lateralized light stimuli. Journal of Experimental Psychology: Human Perception and Performance, Vol. 3, No. 3, 505-517.

Borod, J., Cicero, B., Obler, L., et al. (1998). Right hemisphere emotional perception: evidence across multiple channels. Neuropsychology, 12(3), 446-458.

Brederoo, S. G., Nieuwenstein, M. R., Cornelissen, F. W., \& Lorist, M. M. (2019). Reproducibility of visual-field asymmetries: Nine replication studies investigating lateralization of visual information processing. Cortex, 111, 100126.

Brysbaert, M. (2020). Basic statistics for psychologists ( $2^{\text {nd }}$ edition). Macmillan International Higher Education.

Brysbaert, M. (2019). How Many Participants Do We Have to Include in Properly Powered Experiments? A Tutorial of Power Analysis with Reference Tables. Journal of Cognition, 2(1), 16. DOI: http://doi.org/10.5334/joc.72

Brysbaert, M. \& Nazir, T. (2005). Visual constraints on written word recognition: Evidence from the optimal viewing position effect. Journal of Research in Reading, 28, 216-228. 
Brysbaert, M., \& Stevens, M. (2018). Power Analysis and Effect Size in Mixed Effects Models: A Tutorial. Journal of Cognition, 1:9, 1-20.

Brysbaert, M., Stevens, M., Mandera, P., \& Keuleers, E. (2016). The impact of word prevalence on lexical decision times: Evidence from the Dutch Lexicon Project 2. Journal of Experimental Psychology: Human Perception and Performance, 42(3), 441-458.

Butler, T., O'Mara, E., \& Wilson, J. (2018). Change in drawing placement: A measure of change in mood state reflective of hemispheric lateralization of emotion. Brain Cognition, 124, 14-18.

Button, K. S., Ioannidis, J. P., Mokrysz, C., Nosek, B. A., Flint, J., Robinson, E. S. \& Munafò, M. R. (2013). Power failure: Why small sample size undermines the reliability of neuroscience. Nature Reviews Neuroscience 14(5), 365-376.

Clark, H. H. (1973). The language-as-fixed-effect fallacy: A critique of language statistics in psychological research. Journal of verbal learning and verbal behavior, 12(4), 335-359.

Fanelli, D. (2011). Negative results are disappearing from most disciplines and countries. Scientometrics, 90(3), 891-904.

Ferguson, C. J., \& Heene, M. (2012). A vast graveyard of undead theories: Publication bias and psychological science's aversion to the null. Perspectives on Psychological Science, 7(6), 555-561.

Fox, E., Russo, B., Bowles, R., \& Dutton, K. (2001). Do threatening stimuli draw or hold visual attention in subclinical anxiety? Psychological review, 130(4), 681700.

Franco, A., Malhotra, N., \& Simonovits, G. (2014). Publication bias in the social sciences: Unlocking the file drawer. Science, 345(6203), 1502-1505. 
Fusar-Poli, P., Placentino, A., Carletti, F., Landi, P., Allen, P., Surguladze, S., ...Barale, F. (2009). Functional atlas of emotional faces processing: A voxel-based meta-analysis of 105 functional magnetic resonance imaging studies. Journal of Psychiatry \& Neuroscience, 34, 418-432.

Fussell, Rowe, \& Mohr (2011) Hemispheric processing of differently-valenced and self-relevant attachment words in middle-aged married and separated individuals. Laterality: Asymmetries of Body, Brain and Cognition, 17(4), 453-485.

Holtgraves, T., \& Felton, A. (2011). Hemispheric asymmetry in the processing of negative and positive words: A divided field study. Cognition and Emotion (25), 691-699

Hunter, Z., \& Brysbaert, M. (2008). Visual half-field experiments are a good measure of cerebral language dominance if used properly: Evidence from fMRI. Neuropsychologia, 46, 316-325.

Jończyk, R. (2015). Hemispheric asymmetry of emotion words in a non-native mind: a divided visual field study. Laterality, 20(3), 326-347.

Juhasz, B. J. (2005). Age-of-acquisition effects in word and picture identification. Psychological bulletin, 131(5), 684-712.

Kanske, P., \& Kotz, S.A. (2007). Concreteness in emotional words: ERP evidence from a hemifield study. Brain Res., (7), 138-148.

Keuleers, E., Lacey, P., Rastle, K., \& Brysbaert, M. (2012). The british lexicon project: Lexical decision data for 28,730 monosyllabic and disyllabic english words. Behavior Research Methods, 44, 287-304.

Killgore, W., \& Yurgelun-Todd, D. (2007). The right-hemisphere and valence hypotheses: could they both be right (and sometimes left)? Social Cognitive and 
Affective Neuroscience, 2(3), 240-250.

Kousta, S. T., Vinson, D., \& Vigliocco, G. (2009). Emotion words, regardless of polarity, have a processing advantage over neutral words. Cognition, 112(3), 473-481.

Kuchinke, L., Jacobs, A. M., Grubich, C., Vo, M. L. H., Conrad, M., \& Herrmann, M. (2005). Incidental effects of emotional valence in single word processing: an fMRI study. Neuroimage, 28(4), 1022-1032.

Kuperman, V., Estes, Z., Brysbaert, M., \& Warriner, A. (2014). Emotion and language: Valence and arousal affect word recognition. Journal of experimental psychology. General., 143(3), 1065-1081.

Kuruoglu, G., \& Mergen, F. (2016). Hemispheric Lateralization of Emotion words. An Experimental Study in Turkish-English Bilinguals and Turkish Monolinguals. Philippine Social Sciences and Humanities Review, 5(3), 219-224.

Lang, P.J, Bradley, M.M., \& Cuthbert, M.M. (1997). Motivated attention: Affect, activation and action. Attention and Orienting: Sensory and Motivational Processes, 97-135.

Lindquist, K. A., Wager, T. D., Kober, H., Bliss-Moreau, E., \& Barrett, L. F. (2012). The brain basis of emotion: a meta-analytic review. The Behavioral and brain sciences, 35(3), 121-202.

Martin, J., \& Altarriba, J. (2017). Effects of Valence on Hemispheric Specialization for Emotion Word Processing. Language and speech, 60(4), 597-613.

Mohr, C., Michel, C. M., Lantz, G., Ortigue, S., Viaud-Delmon, I., \& Landis, T. (2005). Brain state-dependent functional hemispheric specialization in men but not in women. Cerebral Cortex, 15, 1451-1458. 
Mohr, C., Rowe, A., \& Craxford, M. (2008). Hemispheric differences in the processing of attachment words. Journal of clinical and experimental neuropsychology, 30(4), 471-480.

Moors, A., De Houwer, J., Hermans, D., Wanmaker, S., van Schie, K., Van Harmelen, A., . . Brysbaert, M. (2013). Norms of Valence, Arousal, Dominance, and Age of Acquisition for 4300 Dutch Words. Behav Res Methods, 45(1), 169-177.

Ocklenburg, S., \& Gunturkun, O. (2018). The lateralized brain: The neuroscience and evolution of hemispheric asymmetries. Academic Press.

Ortigue, S., Michel, C. M., Murray, M. M., Mohr, C., Carbonnel, S., \& Landis, T. (2004). Electrical neuroimaging reveals early generator modulation to emotional words. NeuroImage, 21, 1242-1251.

Perugini, M., Gallucci, M., \& Costantini, G. (2018). A practical primer to power analysis for simple experimental designs. International Review of Social Psychology, $31(1)$.

Price, C.J., \& Devlin, J.T. (2011). The interactive account of ventral occipitotemporal contributions to reading. Trends Cogn Sci, 15, 246-253.

Ramus, F., Altarelli, I., Jednorog, K., Zhao, J., \& Di Covella, L. S. (2018). Neuroanatomy of developmental dyslexia: Pitfalls and promise. Neuroscience \& Biobehavioral Reviews, 84, 434-452.

Rodway, P., Wright, L., \& Hardie, S. (2003). The valence-specific laterality effect in free viewing conditions: the influence of sex, handedness, and response bias. Brain Cogn, 53(3), 452-463.

Strother, L., Zhou, Z., Coros, A. K., \& Vilis, T. (2017). An fMRI study of visual hemifield integration and cerebral lateralization.

Neuropsychologia, 100, 35-43. 
Szaflarski, J., Rajagopal, A., Altaye, M., Bryars, A., Jacola, L., Schmithorst, V., \& Holland, S. (2012). Left-handedness and language lateralization in children. Brain Research, 1433, 85-97.

Van der Haegen, L., Cai, Q., \& Brysbaert, M. (2012). Colateralization of Broca's area and the visual word form area in left-handers: fMRI evidence. Brain and Language, $122,171-178$.

Van der Haegen, L., Cai, Q., Seurinck, R., \& Brysbaert, M. (2011). Further fMRI validation of the visual half field technique as an indicator of language laterality: a large-group analysis. Neuropsychologia 2011, 49, 2879-88.

Vasilev, M. R., Yates, M., \& Slattery, T. J. (2019). Do Readers Integrate Phonological Codes Across Saccades? A Bayesian Meta-Analysis and a Survey of the Unpublished Literature. Journal of Cognition, 2(1), 43. DOI: http://doi.org/10.5334/joc.87

Vingerhoets, G. (2019). Phenotypes in hemispheric functional segregation? Perspectives and challenges. Physics of Life Reviews, 30, 1-18..

Walker, R., \& McSorley, E. (2006). The parallel programming of voluntary and reflexive saccades. Vision Research, 26, 2082-2093.

Wager, T. D., Phan, K. L., Liberzon, I., \& Taylor, S. F. (2003). Valence, gender, and lateralization of functional brain anatomy in emotion: A meta-analysis of findings from neuroimaging. NeuroImage, 19, 513-531.

Wentura, D., Rothermund, K., \& Bak, P. (2000). Automatic vigilance: The attentiongrabbing power of approach- and avoidance-related social information. Journal of Personality and Social Psychology, 78(6), 1024-1037.

Yap, M., \& Seow, C. (2013). The influence of emotion on lexical processing: Insights 
from RT distributional analysis. Psychonomic Bulletin \& Review, 21(2), 526533.

Zhao, G., Zhang, Y., Ge, Y., Zheng, Y., Sun, X. \& Zhang, K. Asymmetric hemisphere activation in tenderness: evidence from EEG signals. (2018). Scientific reports 8(1), Article number: 8029. 
Appendix 1: Stimuli List

\begin{tabular}{|c|c|c|c|c|c|c|c|c|c|c|c|c|}
\hline WORDS & $\begin{array}{l}\text { CATEG } \\
\text { ORY }\end{array}$ & $\begin{array}{l}\text { VALEN } \\
\text { CE }\end{array}$ & $\begin{array}{l}\text { AROUS } \\
\text { AL }\end{array}$ & $\begin{array}{l}\text { LETTE } \\
\text { RS }\end{array}$ & $\begin{array}{l}\text { SYLLA } \\
\text { BLES }\end{array}$ & $\begin{array}{l}\text { FREQU } \\
\text { ENCY }\end{array}$ & $\begin{array}{l}\text { LOGFR } \\
\mathbf{Q}\end{array}$ & AoA & $\begin{array}{l}\text { DOMIN } \\
\text { ANCE }\end{array}$ & $\begin{array}{l}\text { ETENES } \\
\text { S }\end{array}$ & $\begin{array}{l}\text { PREVA } \\
\text { LENCE }\end{array}$ & OLD20 \\
\hline aids & $\mathrm{Neg}$ & 1.47 & 4.69 & 4 & 1 & 156 & 2.19 & 10.45 & 4.38 & 2.80 & 2.00 & 1.80 \\
\hline besmet & $\mathrm{Neg}$ & 2.11 & 4.19 & 6 & 2 & 522 & 2.72 & 7.65 & 3.91 & 2.33 & 2.75 & 1.95 \\
\hline coma & $\mathrm{Neg}$ & 1.75 & 2.08 & 4 & 2 & 616 & 2.79 & 9.06 & 4.03 & 3.27 & 2.19 & 1.55 \\
\hline dief & $\mathrm{Neg}$ & 2.16 & 5.48 & 4 & 1 & 1310 & 3.12 & 5.35 & 4.44 & 4.00 & 2.72 & 1.35 \\
\hline doods & $\mathrm{Neg}$ & 1.72 & 2.52 & 5 & 1 & 301 & 2.48 & 7.90 & 4.11 & 2.33 & 2.02 & 1.65 \\
\hline duivel & $\mathrm{Neg}$ & 1.83 & 5.11 & 6 & 2 & 1973 & 3.30 & 6.94 & 5.64 & 2.53 & 2.82 & 1.60 \\
\hline haat & $\mathrm{Neg}$ & 1.52 & 5.52 & 4 & 1 & 6617 & 3.82 & 6.06 & 5.19 & 1.67 & 2.51 & 1.00 \\
\hline haten & $\mathrm{Neg}$ & 1.61 & 5.67 & 5 & 2 & 1142 & 3.06 & 6.48 & 5.19 & 1.93 & 2.81 & 1.00 \\
\hline incest & $\mathrm{Neg}$ & 1.20 & 5.02 & 6 & 2 & 60 & 1.78 & 11.58 & 4.03 & 2.13 & 1.92 & 2.00 \\
\hline kanker & $\mathrm{Neg}$ & 1.16 & 4.88 & 6 & 2 & 957 & 2.98 & 8.84 & 5.31 & 3.00 & 2.60 & 1.50 \\
\hline lijk & $\mathrm{Neg}$ & 1.73 & 2.30 & 4 & 1 & 3256 & 3.51 & 7.97 & 3.92 & 4.07 & 2.37 & 1.00 \\
\hline moord & Neg & 1.38 & 6.19 & 5 & 1 & 6209 & 3.79 & 7.84 & 5.45 & 3.53 & 3.20 & 1.50 \\
\hline oorlog & $\mathrm{Neg}$ & 1.50 & 6.22 & 6 & 2 & 7826 & 3.89 & 6.39 & 5.97 & 2.87 & 2.86 & 2.05 \\
\hline paniek & $\mathrm{Neg}$ & 2.03 & 6.19 & 6 & 2 & 1743 & 3.24 & 7.03 & 4.20 & 2.73 & 2.86 & 2.00 \\
\hline pest & $\mathrm{Neg}$ & 1.70 & 4.41 & 4 & 1 & 923 & 2.97 & 7.39 & 4.72 & 2.67 & 2.70 & 1.00 \\
\hline pesten & $\mathrm{Neg}$ & 1.67 & 5.58 & 6 & 2 & 282 & 2.45 & 5.68 & 4.66 & 3.40 & 2.78 & 1.00 \\
\hline pijn & Neg & 1.89 & 5.11 & 4 & 1 & 11639 & 4.07 & 3.68 & 4.63 & 3.29 & 2.47 & 1.20 \\
\hline
\end{tabular}




\begin{tabular}{|c|c|c|c|c|c|c|c|c|c|c|c|c|}
\hline ramp & $\mathrm{Neg}$ & 1.61 & 6.02 & 4 & 1 & 1132 & 3.05 & 6.45 & 5.42 & 3.40 & 2.61 & 1.35 \\
\hline rotten & $\mathrm{Neg}$ & 1.95 & 3.86 & 6 & 2 & 283 & 2.45 & 7.19 & 3.92 & 3.67 & 2.49 & 1.00 \\
\hline rotzak & $\mathrm{Neg}$ & 1.88 & 4.89 & 6 & 2 & 926 & 2.97 & 7.52 & 4.66 & 2.27 & 2.64 & 2.00 \\
\hline ruzie & $\mathrm{Neg}$ & 2.14 & 5.95 & 5 & 2 & 2807 & 3.45 & 4.84 & 4.84 & 3.40 & 2.80 & 1.85 \\
\hline schijt & $\mathrm{Neg}$ & 2.03 & 3.81 & 6 & 1 & 370 & 2.57 & 7.03 & 4.33 & 3.87 & 2.18 & 1.65 \\
\hline slaaf & $\mathrm{Neg}$ & 1.89 & 4.23 & 5 & 1 & 776 & 2.89 & 7.48 & 2.05 & 2.93 & 3.01 & 1.45 \\
\hline slecht & $\mathrm{Neg}$ & 2.05 & 4.02 & 6 & 1 & 11711 & 4.07 & 4.48 & 3.67 & 1.60 & 2.88 & 1.65 \\
\hline slet & $\mathrm{Neg}$ & 1.89 & 5.34 & 4 & 1 & 1250 & 3.10 & 10.84 & 3.72 & 2.33 & 2.28 & 1.20 \\
\hline stelen & $\mathrm{Neg}$ & 1.86 & 5.72 & 6 & 2 & 2616 & 3.42 & 6.00 & 4.13 & 3.33 & 3.17 & 1.00 \\
\hline straf & $\mathrm{Neg}$ & 2.36 & 4.78 & 5 & 1 & 1550 & 3.19 & 4.52 & 5.31 & 2.93 & 2.97 & 1.65 \\
\hline stront & $\mathrm{Neg}$ & 1.98 & 3.53 & 6 & 1 & 1203 & 3.08 & 5.74 & 4.00 & 4.53 & 2.11 & 1.80 \\
\hline trauma & $\mathrm{Neg}$ & 1.64 & 5.42 & 6 & 2 & 239 & 2.38 & 9.32 & 4.91 & 2.53 & 2.80 & 2.45 \\
\hline trut & $\mathrm{Neg}$ & 2.14 & 4.61 & 4 & 1 & 1754 & 3.24 & 7.68 & 4.42 & 2.40 & 2.10 & 1.40 \\
\hline tumor & $\mathrm{Neg}$ & 1.45 & 4.91 & 5 & 2 & 9532 & 3.98 & 9.77 & 5.34 & 3.87 & 2.43 & 1.00 \\
\hline vergif & $\mathrm{Neg}$ & 2.06 & 4.44 & 6 & 2 & 451 & 2.65 & 6.16 & 5.19 & 3.80 & 2.40 & 1.85 \\
\hline verlies & $\mathrm{Neg}$ & 2.22 & 3.70 & 7 & 2 & 2146 & 3.33 & 5.55 & 3.25 & 2.20 & 2.78 & 1.60 \\
\hline vies & $\mathrm{Neg}$ & 2.33 & 3.80 & 4 & 1 & 866 & 2.94 & 4.16 & 3.67 & 3.00 & 2.50 & 1.00 \\
\hline vijand & $\mathrm{Neg}$ & 1.88 & 5.34 & 6 & 2 & 2654 & 3.42 & 6.39 & 5.34 & 2.73 & 2.53 & 2.10 \\
\hline vloeken & $\mathrm{Neg}$ & 2.39 & 5.28 & 7 & 2 & 269 & 2.43 & 6.55 & 4.52 & 3.60 & 3.14 & 1.60 \\
\hline wapen & $\mathrm{Neg}$ & 2.38 & 5.31 & 5 & 2 & 6148 & 3.79 & 6.00 & 5.46 & 4.20 & 2.97 & 1.20 \\
\hline woede & $\mathrm{Neg}$ & 2.09 & 5.94 & 5 & 2 & 1091 & 3.04 & 5.35 & 5.30 & 3.27 & 2.64 & 1.40 \\
\hline wraak & $\mathrm{Neg}$ & 2.00 & 5.63 & 5 & 1 & 1925 & 3.28 & 7.65 & 5.22 & 1.93 & 2.68 & 1.65 \\
\hline wurgen & $\mathrm{Neg}$ & 1.66 & 5.98 & 6 & 2 & 221 & 2.34 & 8.10 & 5.17 & 4.13 & 2.71 & 1.65 \\
\hline ziek & $\mathrm{Neg}$ & 2.06 & 2.83 & 4 & 1 & 5650 & 3.75 & 4.16 & 3.00 & 3.20 & 2.89 & 1.20 \\
\hline ziekte & $\mathrm{Neg}$ & 1.78 & 3.92 & 6 & 2 & 1624 & 3.21 & 5.48 & 3.89 & 3.33 & 2.96 & 1.60 \\
\hline aard & Neutr & 4.23 & 3.20 & 4 & 1 & 670.00 & 2.83 & 8.27 & 4.11 & 1.33 & 2.41 & 1.15 \\
\hline accent & Neutr & 4.30 & 3.83 & 6 & 2 & 509 & 2.71 & 8.16 & 4.06 & 3.40 & 2.49 & 1.95 \\
\hline baas & Neutr & 3.73 & 4.92 & 4 & 1 & 7312 & 3.86 & 5.45 & 5.67 & 2.87 & 2.42 & 1.00 \\
\hline baron & Neutr & 4.06 & 3.68 & 5 & 1 & 336 & 2.53 & 8.26 & 5.16 & 3.20 & 2.52 & 1.65 \\
\hline binden & Neutr & 4.02 & 4.53 & 6 & 2 & 393 & 2.59 & 6.58 & 4.38 & 3.40 & 3.03 & 1.00 \\
\hline
\end{tabular}




\begin{tabular}{|c|c|c|c|c|c|c|c|c|c|c|c|c|}
\hline bizar & Neutr & 3.59 & 4.63 & 5 & 2 & 371 & 2.57 & 8.68 & 4.41 & 1.60 & 2.42 & 1.95 \\
\hline butler & Neutr & 4.27 & 4.23 & 6 & 2 & 295 & 2.47 & 8.19 & 2.83 & 4.00 & 2.23 & 1.95 \\
\hline deur & Neutr & 4.13 & 3.56 & 4 & 1 & 10822 & 4.03 & 3.84 & 3.94 & 4.93 & 2.79 & 1.30 \\
\hline dienen & Neutr & 3.56 & 4.14 & 6 & 2 & 1142.00 & 3.06 & 7.55 & 2.52 & 2.47 & 3.32 & 1.60 \\
\hline dokter & Neutr & 4.47 & 4.75 & 6 & 2 & 10673 & 4.03 & 4.19 & 5.00 & 3.60 & 2.63 & 1.75 \\
\hline dozijn & Neutr & 4.16 & 3.48 & 6 & 2 & 346.00 & 2.54 & 8.52 & 4.00 & 3.33 & 2.96 & 1.85 \\
\hline flat & Neutr & 4.03 & 3.30 & 4 & 1 & 1507 & 3.18 & 6.87 & 4.02 & 4.60 & 2.36 & 1.40 \\
\hline front & Neutr & 3.68 & 4.63 & 5 & 1 & 453 & 2.66 & 8.61 & 4.81 & 2.73 & 2.42 & 1.80 \\
\hline gaan & Neutr & 4.27 & 4.66 & 4 & 1 & 115901 & 5.06 & 4.16 & 4.23 & 2.80 & 3.12 & 1.00 \\
\hline gezag & Neutr & 3.94 & 4.64 & 5 & 2 & 510.00 & 2.71 & 8.16 & 5.77 & 1.80 & 2.58 & 1.70 \\
\hline grens & Neutr & 3.89 & 3.52 & 5 & 1 & 1660 & 3.22 & 6.52 & 4.31 & 3.00 & 2.80 & 1.60 \\
\hline hand & Neutr & 4.36 & 3.95 & 4 & 1 & 8742 & 3.94 & 3.87 & 4.03 & 4.87 & 3.15 & 1.20 \\
\hline handel & Neutr & 4.20 & 4.72 & 6 & 2 & 1139.00 & 3.06 & 7.81 & 4.25 & 2.80 & 2.96 & 1.50 \\
\hline hertog & Neutr & 4.36 & 3.84 & 6 & 2 & 429 & 2.63 & 8.16 & 5.14 & 2.93 & 2.68 & 1.95 \\
\hline jaar & Neutr & 4.22 & 3.44 & 4 & 1 & 33351 & 4.52 & 4.19 & 4.02 & 2.07 & 2.88 & 1.15 \\
\hline kabel & Neutr & 4.02 & 3.48 & 5 & 2 & 427 & 2.63 & 6.61 & 4.06 & 4.60 & 2.50 & 1.35 \\
\hline kanaal & Neutr & 4.06 & 3.46 & 6 & 2 & 610 & 2.79 & 7.42 & 4.00 & 4.07 & 2.80 & 1.70 \\
\hline kantoor & Neutr & 3.94 & 3.95 & 7 & 2 & 5441 & 3.74 & 6.84 & 4.05 & 4.47 & 2.71 & 1.95 \\
\hline kelner & Neutr & 4.29 & 4.64 & 6 & 2 & 102 & 2.01 & 8.68 & 3.11 & 4.20 & 2.19 & 1.80 \\
\hline kool & Neutr & 4.00 & 3.25 & 4 & 1 & 207 & 2.32 & 6.61 & 3.53 & 4.33 & 2.58 & 1.15 \\
\hline laden & Neutr & 3.92 & 4.67 & 5 & 2 & 468 & 2.67 & 6.74 & 4.06 & 3.53 & 2.76 & 1.00 \\
\hline liter & Neutr & 4.19 & 3.52 & 5 & 2 & 377 & 2.58 & 6.58 & 3.86 & 3.60 & 2.66 & 1.60 \\
\hline lossen & Neutr & 3.84 & 4.36 & 6 & 2 & 1021 & 3.01 & 6.94 & 3.80 & 3.20 & 2.66 & 1.00 \\
\hline luik & Neutr & 3.95 & 3.27 & 4 & 1 & 292 & 2.47 & 6.58 & 3.91 & 4.67 & 2.65 & 1.10 \\
\hline massa & Neutr & 3.78 & 4.78 & 5 & 2 & 409 & 2.61 & 8.13 & 5.30 & 2.93 & 2.53 & 1.85 \\
\hline middel & Neutr & 4.17 & 3.73 & 6 & 2 & 634 & 2.80 & 6.71 & 4.02 & 2.47 & 3.18 & 1.85 \\
\hline naam & Neutr & 4.44 & 3.48 & 4 & 1 & 20579 & 4.31 & 3.68 & 4.19 & 2.60 & 2.86 & 1.30 \\
\hline orgaan & Neutr & 3.98 & 4.25 & 6 & 2 & 107 & 2.03 & 8.71 & 4.33 & 4.27 & 2.62 & 1.85 \\
\hline plots & Neutr & 3.80 & 5.31 & 5 & 1 & 509 & 2.71 & 6.65 & 4.40 & 1.60 & 3.21 & 1.65 \\
\hline pomp & Neutr & 4.09 & 4.14 & 4 & 1 & 290 & 2.46 & 6.74 & 3.91 & 4.53 & 2.57 & 1.45 \\
\hline
\end{tabular}




\begin{tabular}{|c|c|c|c|c|c|c|c|c|c|c|c|c|}
\hline posten & Neutr & 4.19 & 4.14 & 6 & 2 & 188 & 2.27 & 6.52 & 3.91 & 3.33 & 2.50 & 1.00 \\
\hline rekken & Neutr & 3.86 & 4.50 & 6 & 2 & 189 & 2.28 & 7.00 & 3.88 & 3.67 & 3.21 & 1.00 \\
\hline schoen & Neutr & 4.31 & 3.53 & 6 & 1 & 588.00 & 2.77 & 3.90 & 3.69 & 4.80 & 2.64 & 1.55 \\
\hline stelt & Neutr & 3.93 & 3.65 & 5 & 1 & 2374 & 3.38 & 6.74 & 3.95 & 3.92 & 2.40 & 1.20 \\
\hline stil & Neutr & 4.13 & 1.84 & 4 & 1 & 7032 & 3.85 & 3.97 & 3.31 & 3.20 & 2.68 & 1.40 \\
\hline stoel & Neutr & 4.25 & 2.75 & 5 & 1 & 2239.00 & 3.35 & 3.74 & 3.73 & 4.67 & 3.15 & 1.30 \\
\hline sultan & Neutr & 4.11 & 3.88 & 6 & 2 & 180 & 2.26 & 8.42 & 5.48 & 3.33 & 2.27 & 2.05 \\
\hline systeem & Neutr & 4.28 & 3.69 & 7 & 2 & 2004.00 & 3.30 & 8.68 & 4.48 & 1.60 & 3.22 & 2.95 \\
\hline terrein & Neutr & 4.05 & 3.50 & 7 & 2 & 1183 & 3.07 & 6.81 & 4.19 & 3.47 & 2.80 & 2.20 \\
\hline testen & Neutr & 4.08 & 4.81 & 6 & 2 & 1187 & 3.07 & 6.61 & 4.27 & 2.60 & 3.18 & 1.10 \\
\hline toestel & Neutr & 4.13 & 3.67 & 7 & 2 & 714 & 2.85 & 6.48 & 3.89 & 3.07 & 2.89 & 1.85 \\
\hline vatten & Neutr & 4.20 & 4.28 & 6 & 2 & 221 & 2.34 & 8.32 & 4.19 & 1.87 & 2.36 & 1.00 \\
\hline vinger & Neutr & 4.31 & 3.95 & 6 & 2 & 1264.00 & 3.10 & 3.74 & 3.63 & 4.87 & 2.66 & 1.70 \\
\hline vlak & Neutr & 3.89 & 2.81 & 4 & 1 & 2087 & 3.32 & 7.00 & 3.75 & 3.07 & 2.66 & 1.25 \\
\hline vuur & Neutr & 3.95 & 5.30 & 4 & 1 & 4398 & 3.64 & 4.42 & 5.69 & 4.73 & 2.49 & 1.40 \\
\hline attent & Pos & 5.80 & 4.39 & 6 & 2 & 309 & 2.49 & 9.29 & 4.47 & 1.67 & 2.29 & 1.90 \\
\hline bemind & Pos & 5.91 & 4.44 & 6 & 2 & 84 & 1.92 & 9.32 & 4.71 & 1.87 & 2.36 & 1.60 \\
\hline blij & Pos & 6.25 & 5.36 & 4 & 1 & 12126 & 4.08 & 3.71 & 4.95 & 2.27 & 2.75 & 1.60 \\
\hline dapper & Pos & 5.83 & 5.25 & 6 & 2 & 942 & 2.97 & 6.23 & 5.42 & 2.00 & 2.44 & 1.55 \\
\hline dolblij & Pos & 6.39 & 5.89 & 7 & 2 & 115 & 2.06 & 6.48 & 5.30 & 2.60 & 2.51 & 2.75 \\
\hline feest & Pos & 6.17 & 5.98 & 5 & 1 & 4297 & 3.63 & 4.77 & 4.92 & 3.93 & 2.49 & 1.30 \\
\hline fier & Pos & 5.53 & 4.59 & 4 & 1 & 94 & 1.97 & 8.03 & 5.14 & 2.40 & 2.56 & 1.10 \\
\hline galant & Pos & 5.69 & 3.94 & 6 & 2 & 52 & 1.72 & 9.87 & 4.54 & 2.20 & 2.20 & 1.80 \\
\hline geliefd & Pos & 6.28 & 4.27 & 7 & 2 & 316 & 2.50 & 7.42 & 5.14 & 1.80 & 2.58 & 1.50 \\
\hline geluk & Pos & 6.39 & 4.73 & 5 & 2 & 7260 & 3.86 & 6.26 & 5.41 & 1.47 & 3.25 & 1.65 \\
\hline genot & Pos & 6.13 & 4.91 & 5 & 2 & 355 & 2.55 & 9.23 & 5.13 & 2.33 & 2.66 & 1.30 \\
\hline gezond & Pos & 6.28 & 4.48 & 6 & 2 & 1392 & 3.14 & 5.97 & 5.22 & 2.13 & 3.32 & 1.55 \\
\hline gratis & Pos & 5.89 & 3.81 & 6 & 2 & 1984 & 3.30 & 6.10 & 4.39 & 2.13 & 2.95 & 1.90 \\
\hline held & Pos & 5.88 & 5.47 & 4 & 1 & 2608 & 3.42 & 5.84 & 5.67 & 2.07 & 3.13 & 1.35 \\
\hline hoop & Pos & 5.84 & 4.34 & 4 & 1 & 16085 & 4.21 & 6.35 & 4.72 & 1.67 & 2.82 & 1.10 \\
\hline
\end{tabular}




\begin{tabular}{|c|c|c|c|c|c|c|c|c|c|c|c|c|}
\hline humor & Pos & 6.11 & 5.17 & 5 & 2 & 857 & 2.93 & 7.29 & 5.13 & 2.13 & 2.85 & 2.00 \\
\hline intiem & Pos & 5.83 & 5.09 & 6 & 2 & 264 & 2.42 & 9.45 & 4.75 & 2.27 & 2.50 & 1.95 \\
\hline knap & Pos & 5.97 & 4.45 & 4 & 1 & 2976 & 3.47 & 5.71 & 4.91 & 2.33 & 3.21 & 1.30 \\
\hline knus & Pos & 5.81 & 3.02 & 4 & 1 & 103 & 2.01 & 7.52 & 3.95 & 2.67 & 2.84 & 1.60 \\
\hline lachen & Pos & 6.36 & 5.34 & 6 & 2 & 3887 & 3.59 & 4.42 & 4.80 & 3.93 & 2.69 & 1.85 \\
\hline leuk & Pos & 5.94 & 4.83 & 4 & 1 & 26044 & 4.42 & 4.03 & 4.42 & 1.80 & 3.19 & 1.25 \\
\hline lief & Pos & 6.25 & 4.08 & 4 & 1 & 4983 & 3.70 & 4.03 & 4.22 & 2.13 & 2.73 & 1.00 \\
\hline liefde & Pos & 6.53 & 5.59 & 6 & 1 & 9135 & 3.96 & 5.84 & 5.58 & 1.87 & 2.69 & 1.60 \\
\hline loyaal & Pos & 5.92 & 3.95 & 6 & 2 & 235 & 2.37 & 10.68 & 4.72 & 1.87 & 2.60 & 1.90 \\
\hline mooi & Pos & 6.13 & 4.20 & 4 & 1 & 26940 & 4.43 & 3.84 & 4.78 & 2.07 & 2.65 & 1.05 \\
\hline passie & Pos & 6.09 & 5.88 & 6 & 2 & 646 & 2.81 & 9.00 & 5.50 & 1.87 & 2.69 & 1.85 \\
\hline plezier & Pos & 6.22 & 5.39 & 7 & 2 & 5475 & 3.74 & 5.03 & 4.97 & 2.13 & 2.85 & 1.85 \\
\hline pret & Pos & 6.00 & 5.42 & 4 & 1 & 395 & 2.60 & 5.55 & 4.63 & 2.60 & 2.70 & 1.25 \\
\hline reis & Pos & 5.86 & 4.84 & 4 & 1 & 3952 & 3.60 & 5.39 & 4.31 & 3.47 & 3.17 & 1.00 \\
\hline schat & Pos & 5.94 & 4.44 & 5 & 1 & 11546 & 4.06 & 5.29 & 4.92 & 3.40 & 2.68 & 1.40 \\
\hline slim & Pos & 5.86 & 4.48 & 4 & 1 & 4878 & 3.69 & 4.90 & 5.20 & 2.00 & 2.44 & 1.45 \\
\hline succes & Pos & 6.09 & 5.33 & 6 & 2 & 4532 & 3.66 & 6.77 & 5.56 & 1.67 & 2.70 & 2.80 \\
\hline super & Pos & 6.22 & 5.17 & 5 & 2 & 930 & 2.97 & 5.32 & 5.11 & 1.27 & 2.86 & 1.90 \\
\hline talent & Pos & 6.09 & 4.59 & 6 & 2 & 1566 & 3.19 & 7.16 & 5.14 & 1.67 & 2.80 & 1.90 \\
\hline triomf & Pos & 5.63 & 5.31 & 6 & 2 & 151 & 2.18 & 9.26 & 5.45 & 2.29 & 2.07 & 2.35 \\
\hline trots & Pos & 5.72 & 4.86 & 5 & 1 & 4874 & 3.69 & 6.55 & 5.08 & 1.80 & 2.82 & 1.55 \\
\hline trouw & Pos & 6.00 & 4.42 & 5 & 1 & 2289 & 3.36 & 7.00 & 4.89 & 2.67 & 2.82 & 1.70 \\
\hline vitaal & Pos & 5.54 & 5.06 & 6 & 2 & 47 & 1.67 & 10.93 & 5.16 & 1.80 & 2.30 & 1.95 \\
\hline vrede & Pos & 6.42 & 2.83 & 5 & 2 & 2843 & 3.45 & 6.10 & 5.20 & 1.80 & 3.18 & 1.60 \\
\hline vredig & Pos & 5.91 & 2.69 & 6 & 2 & 300 & 2.48 & 7.61 & 4.34 & 1.80 & 2.32 & 1.95 \\
\hline vreugde & Pos & 6.30 & 5.39 & 7 & 2 & 593 & 2.77 & 6.19 & 4.91 & 2.60 & 3.19 & 1.90 \\
\hline vriend & Pos & 6.30 & 4.48 & 6 & 1 & 21490 & 4.33 & 4.03 & 4.95 & 2.40 & 2.62 & 1.85 \\
\hline vrij & Pos & 5.98 & 3.95 & 4 & 1 & 10185 & 4.01 & 5.13 & 5.05 & 1.73 & 2.57 & 1.70 \\
\hline vrijen & Pos & 6.16 & 6.33 & 6 & 2 & 1001 & 3.00 & 9.61 & 5.16 & 3.80 & 3.14 & 1.60 \\
\hline winnen & Pos & 5.94 & 5.83 & 6 & 2 & 5097 & 3.71 & 5.13 & 5.23 & 2.80 & 2.60 & 1.10 \\
\hline
\end{tabular}




\begin{tabular}{|c|c|c|c|c|c|c|c|c|c|c|c|c|}
\hline winst & Pos & 5.77 & 4.83 & 5 & 1 & 946 & 2.98 & 7.39 & 5.08 & 2.27 & 2.49 & 1.50 \\
\hline wonder & Pos & 6.13 & 5.03 & 6 & 2 & 1964 & 3.29 & 6.26 & 5.27 & 1.87 & 2.79 & 1.40 \\
\hline zalig & Pos & 6.34 & 4.06 & 5 & 2 & 400 & 2.60 & 7.26 & 4.73 & 2.07 & 2.88 & 1.70 \\
\hline zoen & Pos & 6.02 & 5.20 & 4 & 1 & 437 & 2.64 & 4.23 & 4.61 & 4.67 & 2.35 & 1.00 \\
\hline zomer & Pos & 6.17 & 4.33 & 5 & 2 & 1876 & 3.27 & 5.23 & 4.63 & 2.53 & 2.88 & 1.50 \\
\hline
\end{tabular}

Valence, arousal, prevalence, concreteness, OLD20 (similarity to other words)= 7-point Likert Scale.

Letters/syllables $=$ amount of letters/syllables.

Frequency $=$ how frequent the word is.

Age of Acquisition $(\operatorname{AoA})=$ mean year at which the word is acquired. 